\title{
Late Onset Peripheral Spondyloarthritis in Woman with Hashimoto's Thyroiditis: A Case Report
}

\author{
Mounib M. Sabounji, Aïssatou Ndiaye, Laurine M. Adogble \\ Department of Rheumatology, Aristide Le Dantec Hospital, Cheikh Anta Diop University, Dakar, Senegal \\ Email: sabounji.mounib@gmail.com
}

How to cite this paper: Sabounji, M.M., Ndiaye, A. and Adogble, L.M. (2021) Late Onset Peripheral Spondyloarthritis in Woman with Hashimoto's Thyroiditis: A Case Report. Case Reports in Clinical Medicine, 10, 277-283.

https://doi.org/10.4236/crcm.2021.1010035

Received: August 25, 2021

Accepted: October 15, 2021

Published: October 18, 2021

Copyright ( 2021 by author(s) and Scientific Research Publishing Inc. This work is licensed under the Creative Commons Attribution International License (CC BY 4.0).

http://creativecommons.org/licenses/by/4.0/

\begin{abstract}
Late onset peripheral spondyloarthritis is a particular clinical form of spondyloarthritis, occurring at the age of 50 years or older. Hashimoto's thyroiditis (HT) is the most frequent autoimmune thyroid disorder responsible for considerable morbidity. HT is well known to be associated with many systemic autoimmune, it is less clear whether a similar association may also be present for spondyloarthritis. Here, we report a case of late onset peripheral spondyloarthritis in a 62-year-old African woman with a 12-year history of Hashimoto's thyroiditis, a previously undescribed association in the literature. The diagnosis of Late onset peripheral spondyloarthritis was made according to the Assessment of SpondyloArthritis international Society (ASAS) criteria for peripheral spondyloarthritis (presence of arthritis, enthesitis and Human Leukocyte Antigen B27). She was treated with methotrexate and celebid. After 6 months of treatment, the evolution was favourable with an overall improvement in her symptomatology and quality of life. The coexistence of late onset peripheral spondyloarthritis and Hashimoto's thyroiditis may be related to the presence of a genetic background predisposing to both diseases.
\end{abstract}

\section{Keywords}

Late Onset, Peripheral Spondyloarthritis, Hashimoto's Thyroiditis

\section{Introduction}

Late onset peripheral spondyloarthritis (LOPS) is a particular clinical form of spondyloarthritis $(\mathrm{SpA})$, characterized by a mildly inflammatory oligoarthritis contrasting with general signs (fever or weight loss), an important inflammatory 
syndrome and sometimes asymmetric oedema of the lower limbs [1], occurring at the age of 50 years or older [2] [3] [4]. On the other hand, Hashimoto's thyroiditis (HT) is the most frequent autoimmune thyroid disorder responsible for considerable morbidity [5]. It is characterized by diffuse lymphocytic infiltration of the thyroid gland, elevated levels of the serum antithyroid antibodies, clinical evidence of goitrous or atrophic gland, and frequent thyroid dysfunction in varying degrees [6]. Although HT is well known to be associated with many systemic autoimmune, it is less clear whether a similar association may also be present for SpA. Here, we report the case of an elderly woman with diagnosis of Hashimoto thyroiditis, exhibiting late onset peripheral spondyloarthritis. The relevance of this case is the presentation of Hashimoto's thyroiditis with LOPS, entities that generally do not coexist, allowing us to do a literature review and report this as the first clinical association seen in our region.

\section{Case Report}

A 62-year-old Senegalese female, was diagnosed with Hashimoto thyroiditis at the age of 50 years, based on the presence of anti-thyroperoxydase antibody, anti-thyrogluline antibody and ultrasonography findings showed an atrophic thyroid with parenchymal heterogeneity. At that time, thyroid dysfunction was already present: TSHus: $53.54 \mathrm{mUI} / \mathrm{L}(0.27$ - $4.20 \mathrm{mUI} / \mathrm{L})$, T4L: 8.93 pmol/l (12 $22 \mathrm{pmol} / \mathrm{l})$. With these results, medical treatment consisting on $200 \mathrm{mcg} / \mathrm{day}$ of levothyroxine was prescribed.

In December 2020, she was admitted to our department of rheumatology because of joint pain for half a year. Her past medical history and her family history were negative for spondyloarthritis. She denied any history of conjunctivitis, uveitis, diarrhea, urethritis, psoriasis. On admission, vital signs including body temperature were normal, body mass index was normal $24.7 \mathrm{~kg} / \mathrm{m}^{2}$, and chest auscultation revealed normal vesicular breath sounds and heart sounds. Lower extremities were found without edema, muscle stretching reflexes were found to be normal. The rheumatological examination showed a peripheral oligoarthritis of the lower limbs, involving the right knee, right ankle, and enthesitis of the right Achilles tendon with plantar fasciitis. Otherwise, she had no axial involvement such as low back pain or sacroiliac pain. The Bath Ankylosing Spondylitis Disease Activity Index (BASDAI) was 4.02/10 and Ankylosing Spondylitis Quality of Life (ASQoL) was 9/18.

Laboratory tests showed: elevated C-reactive protein (CRP) $12 \mathrm{mg} / \mathrm{l}$ (normal < $6 \mathrm{mg} / \mathrm{l}$ ), erythrocyte sedimentation rate (ESR) was $18 \mathrm{~mm} / \mathrm{h}$ (normal 0 to $14 \mathrm{~mm}$ per hour), HLA-B27 was positive. Blood count, Lipid Panel, Creatinine, Uric acid, Calcemia, Albumin, Glucose all within normal limit. Negative test results included rheumatoid factor (RF), anti-cyclic citrullinated peptide antibody, antinuclear antibody (ANA), anti-DNA antibody. Other laboratory data are summarized in Table 1.

The diagnosis of late onset peripheral spondyloarthritis was made based on 
Table 1. Summary of laboratory data at admission.

\begin{tabular}{|c|c|c|}
\hline Laboratory test & Result & Reference range \\
\hline \multicolumn{3}{|l|}{ Blood count } \\
\hline Hemoglobin & $12.5 \mathrm{~g} / \mathrm{dl}$ & $12-16$ \\
\hline Mean corpuscular volume & $87.5 \mathrm{fl}$ & $80-99$ \\
\hline Mean corpuscular hemoglobine & $27.4 \mathrm{pg}$ & $27-32$ \\
\hline White blood cell & $4600 / \mathrm{mm}^{3}$ & $4000-8000$ \\
\hline Platelets & $190.000 / \mathrm{mm}^{3}$ & $150.000-450.000$ \\
\hline Lymphocytes & $3100 / \mathrm{mm}^{3}$ & $1500-5000$ \\
\hline \multicolumn{3}{|l|}{ Biochemistry } \\
\hline CRP & $12 \mathrm{mg} / \mathrm{l}$ & Normal $<6 \mathrm{mg} / \mathrm{l}$ \\
\hline Creatinine & $8.1 \mathrm{mg} / \mathrm{l}$ & $5.1-9.5$ \\
\hline Calcemia & $92 \mathrm{mg} / \mathrm{l}$ & $84-102$ \\
\hline Uric acid & $57.3 \mathrm{mg} / \mathrm{l}$ & $24-60$ \\
\hline \multicolumn{3}{|l|}{ Thyroid function } \\
\hline TSHus & $53.54 \mathrm{mUI} / \mathrm{l}$ & $0.27-4.20$ \\
\hline $\mathrm{T} 4 \mathrm{~L}$ & $8.93 \mathrm{pmol} / 1$ & $12-22$ \\
\hline Anti-thyrogluline antibody & $55 \mathrm{IU} / \mathrm{ml}$ & $0-5$ \\
\hline Anti-thyroperoxydase antibody & $21.6 \mathrm{IU} / \mathrm{ml}$ & $0-5.5$ \\
\hline \multicolumn{3}{|l|}{ Genetic } \\
\hline HLA-B27 Antigen & Positive & Negative \\
\hline \multicolumn{3}{|l|}{ Immunology } \\
\hline Rheumatoid factor & Negative & Negative \\
\hline Anti-cyclic citrullinated peptide antibody & Negative & Negative \\
\hline Anti-nuclear antibody & Negative & Negative \\
\hline Anti-DNA antibody & Negative & Negative \\
\hline Anti-SSA/Ro 52 antibody & Negative & Negative \\
\hline Anti-SSB/Ro 60 antibody & Negative & Negative \\
\hline Anti-Sm antibody & Negative & Negative \\
\hline Anti-centromere antibody & Negative & Negative \\
\hline Anti-Scl70 antibody & Negative & Negative \\
\hline Anti-U1 RNP antibody & Negative & Negative \\
\hline
\end{tabular}

the ASAS peripheral spondyloarthritis criteria (arthritis, enthesitis plus HLA-B27 positive) [7] and age of onset $\geq 50$ years [4].

The patient was treated with conventional synthetic disease-modifying anti-rheumatic drugs (csDMARDs): methotrexate $20 \mathrm{mg}$ per week, and non-steroidal anti-inflammatory drugs (NSAIDs): Celecoxib $100 \mathrm{mg} / 12 \mathrm{~h}$. After 6 months of treatment the patient had a BASDAI of 1.92/10 and ASQoL 4/18, with improve- 
ment of clinical symptoms and quality of life.

\section{Discussion}

Spondyloarthrite $(\mathrm{SpA})$ are usually observed in young patients and a clinical onset after 50 years is uncommon [8]. As we are in the context of an aging population and a longer life expectancy, one may believe that the prevalence of patients with late-onset SpA will rise [4]. Indeed, a true diagnosis of SpA beyond age 50 years is rare and most patients diagnosed as elderly onset correspond to "normal"-onset disease but with delayed recognition due to atypical presentation, especially in women. In addition, late-onset $\mathrm{SpA}$ may be mistaken for other diseases that are common after the age of 50 years such as rheumatoid arthritis, polymyalgia rheumatica, or even osteoarthritis [4].

The full clinical spectrum of SpA may be observed in the elderly, with two or three predominant clinical features including late-onset peripheral Spondyloarthrite [1], which was first described by Dubost and Sauvezie in 1989 and called "LOPS" for Late-Onset Peripheral Spondyloarthrite [9]. Generally, peripheral spondyloathritis manifestations are asymmetrical mono-articular or oligoarticular (less than five joints) inflammatory arthritis that involves the lower limbs more frequently than the upper limbs, heel enthesitis and dactylitis [10] [11]. Typically, LOPS consisting of mild inflammatory oligoarthritis, general signs such as fever or weight loss, are frequent, but are absent in $29 \%$ of cases, important inflammatory syndrome, and sometimes asymmetrical edema on the legs [1].

No global diagnostic algorithm for peripheral $\mathrm{SpA}$ has been developed to date; and diagnosis is essentially clinical based on the presence of several signs and symptoms as discussed above [10]. Otherwise, HLA-B27 testing was quite useful for the diagnosis, indeed in French study, 70\% of late onset spondyloarthritis patients were determined to be HLA-B27 positive [12]. However, Assessment of SpondyloArthritis international Society (ASAS) criteria for peripheral spondyloarthritis [7] refer to patients under 45 years of age and were not specifically evaluated in the aging population with peripheral arthritis/enthesitis/dactylitis; however, they can facilitate the diagnosis of late-onset peripheral spondyloarthritis [4].

Although Hashimoto's thyroiditis is well known to be associated with many systemic autoimmune diseases such as primary Sjögren's syndrome, systemic lupus erythematosus, and rheumatoid arthritis, possibly due to a common genetic background, it is less clear whether a similar association may also be present for spondyloarthritis [13]. If there is really an association between SpA and autoimmune thyroid diseases, this might be due to common genetic pathogenic mechanisms predisposing to these two disorders. Since the frequency of HLA-B27 has been suggested to be important in the pathogenesis of SpA contributing to $20.1 \%$ of spondyloarthritis heritability [14] [15], was reported to be four times higher in autoimmune endocrinopathies than in healthy controls 
[16], HLA-B27 positivity may also have an additional role in the pathogenesis of HT [13]. More recently, another molecule known as cytotoxic T-lymphocyte antigen 4 (CTLA-4) that have been implicated specifically in the pathogenesis of HT [17] [18]. Indeed, Toussirot et al. [19] reported that this same molecule was implicated in the pathogenesis of SpA. Therefore, it may be speculated that both HLA-B27 and CTLA-4 may contribute to the coexistence of these two diseases, possibly playing a role in the pathogenesis of both SpA and HT [13].

Our patient was treated with NSAIDs and csDMARDs (methotrexate), however no specific recommendations for peripheral spondyloarthritis management have been published. The ASAS-EULAR recommendations for axial SpA management [20] include recommendations for management of peripheral manifestations [10]. The EULAR management recommendations mainly deal with peripheral arthritis. A step-up treatment schedule is proposed, starting with NSAIDs, followed by csDMARDs (with methotrexate as the anchor drug), then biological agents, usually a TNF blocker [20]. NSAIDs are widely used in daily clinical practice for the initial treatment of any type of arthritis, and also recommended as the initial treatment choice in patients with peripheral enthesitis or dactylitis, despite the absence of specific studies. In patients with persistently active disease because of an inadequate response to the initial therapy, a csDMARDs, such as sulfasalazine ( 2 to $3 \mathrm{~g}$ daily), methotrexate (MTX, up to $25 \mathrm{mg}$ once weekly) or leflunomide (20 mg daily), can be initiated [11].

\section{Conclusion}

To our knowledge, this is the first case report showing the association of late onset peripheral spondyloarthritis and Hashimoto's thyroiditis. As mentioned above, the relationship between SpA and HT may be related to the presence of a genetic background predisposing to both diseases. In our case, the presence of HLA-B27 was an essential argument for the diagnosis.

\section{Conflicts of Interest}

The authors declare no conflicts of interest regarding the publication of this paper.

\section{References}

[1] Dubost, J.-J., Tournadre, A. and Soubrier, M. (2019) Les Spondyloarthrites à début tardif. Revue du Rhumatisme Monographies, 86, 190-194.

https://doi.org/10.1016/j.monrhu.2019.01.001

[2] Montilla, C., Pino-Montes, J.D., Collantes-Estevez, E., Font, P., Zarco, P., Mulero, J., et al. (2012) Clinical Features of Late-Onset Ankylosing Spondylitis: Comparison with Early-onset Disease. The Journal of Rheumatology, 39, 1008-1012. https://doi.org/10.3899/jrheum.111082

[3] Toussirot, E. (2010) Late-Onset Ankylosing Spondylitis and Spondylarthritis: An Update on Clinical Manifestations, Differential Diagnosis and Pharmacological Therapies. Drugs \& Aging, 27, 523-531. 
https://doi.org/10.2165/11315970-000000000-00000

[4] Toussirot, É. (2015) Diagnosis and Management of Late-Onset Spondyloarthritis: Implications of Treat-to-Target Recommendations. Drugs \& Aging, 32, 515-524. https://doi.org/10.1007/s40266-015-0280-y

[5] Ragusa, F., Fallahi, P., Elia, G., Gonnella, D., Paparo, S.R., Giusti, C., et al. (2019) Hashimoto's Thyroiditis: Epidemiology, Pathogenesis, Clinic and Therapy. Best Practice \& Research Clinical Endocrinology \& Metabolism, 33, Article ID: 101367. https://doi.org/10.1016/j.beem.2019.101367

[6] Punzi, L. and Betterle, C. (2004) Chronic Autoimmune Thyroiditis and Rheumatic Manifestations. Joint Bone Spine, 71, 275-283.

https://doi.org/10.1016/j.jbspin.2003.06.005

[7] Rudwaleit, M., van der Heijde, D., Landewé, R., Akkoc, N., Brandt, J., Chou, C.T., et al. (2011) The Assessment of SpondyloArthritis International Society Classification Criteria for Peripheral Spondyloarthritis and for Spondyloarthritis in General. Annals of the Rheumatic Diseases, 70, 25-31. https://doi.org/10.1136/ard.2010.133645

[8] Olivieri, I., D’Angelo, S., Padula, A., Leccese, P. and Palazzi, C. (2013) Spondyloarthritis with Onset after Age 45. Current Rheumatology Reports, 15, Article No. 374. https://doi.org/10.1007/s11926-013-0374-7

[9] Dubost, J.J. and Sauvezie, B. (1989) Late Onset Peripheral Spondylarthropathy. The Journal of Rheumatology, 16, 1214-1217.

[10] Molto, A. and Sieper, J. (2018) Peripheral Spondyloarthritis: Concept, Diagnosis and Treatment. Best Practice \& Research Clinical Rheumatology, 32, 357-368. https://doi.org/10.1016/j.berh.2019.02.010

[11] Carron, P., De Craemer, A.-S. and Van den Bosch, F. (2020) Peripheral Spondyloarthritis: A Neglected Entity-State of the Art. RMD Open, 6, e001136. https://doi.org/10.1136/rmdopen-2019-001136

[12] Dubost, J.J. and Sauvezie, B. (1992) Current Aspects of Inflammatory Rheumatic Diseases in Elderly Patients. Revue du Rhumatisme et Des Maladies Ostéo-Articulaires, 59, 37S-42S.

[13] Emmungil, H., Erdogan, M., Kalfa, M., Karabulut, G., Kocanaogulları, H., Inal, V., et al. (2014) Autoimmune Thyroid Disease in Ankylosing Spondylitis. Clinical Rheumatology, 33, 955-961. https://doi.org/10.1007/s10067-013-2466-1

[14] Chatzikyriakidou, A., Voulgari, P.V. and Drosos, A.A. (2011) What Is the Role of HLA-B27 in Spondyloarthropathies? Autoimmunity Reviews, 10, 464-468.

https://doi.org/10.1016/j.autrev.2011.01.011

[15] Chen, B., Li, J., He, C., Li, D., Tong, W., Zou, Y., et al. (2017) Role of HLA-B27 in the Pathogenesis of Ankylosing Spondylitis (Review). Molecular Medicine Reports, 15, 1943-1951. https://doi.org/10.3892/mmr.2017.6248

[16] Hrdá, P., Sterzl, I., Matucha, P., Korioth, F. and Kromminga, A. (2004) HLA Antigen Expression in Autoimmune Endocrinopathies. Physiological Research, 53, 191-197.

[17] Qiu, H., Tang, W., Yin, P., et al. (2014) Cytotoxic T-Lymphocyte Associated Antigen 4 Polymorphism and Hashimoto'S Thyroiditis Susceptibility: A Meta-Analysis. Endocrine, 45, 198-205. https://doi.org/10.1007/s12020-013-9985-z

[18] Hu, Y., Xu, K., Jiang, L., Zhang, L., Shi, H. and Cui, D. (2018) Associations between Three CTLA-4 Polymorphisms and Hashimoto's Thyroiditis Risk: An Updated Meta-Analysis with Trial Sequential Analysis. Genetic Testing and Molecular Biomarkers, 22, 224-236. https://doi.org/10.1089/gtmb.2017.0243

[19] Toussirot, E., Saas, P., Deschamps, M., Pouthier, F., Perrot, L., Perruche, S., et al. 
(2009) Increased Production of Soluble CTLA-4 in Patients with Spondylarthropathies Correlates with Disease Activity. Arthritis Research \& Therapy, 11, Article No. R101. https://doi.org/10.1186/ar2747

[20] Van der Heijde, D., Ramiro, S., Landewé, R., et al. (2017) 2016 Update of the ASASEULAR Management Recommendations for Axial Spondyloarthritis. Annals of the Rheumatic Diseases, 76, 978-991.

https://doi.org/10.1136/annrheumdis-2016-210770 